\title{
Segmentation of rock sample's micro-CT images for computing porosity on open source software
}

Alessandra Camilli Meletani*, Irosvaldo Ferreira de Carvalho Filho, Milton Morais Xavier Júnior, Departamento de Geofísica, UFRN

Copyright 2021, SBGf - Sociedade Brasileira de Geofísica.

This paper was prepared for presentation during the $17^{\text {th }}$ International Congress of the Brazilian Geophysical Society held in Rio de Janeiro, Brazil, 8-11 November 2021 .

Contents of this paper were reviewed by the Technical Committee of the $17^{\text {th }}$ International Congress of the Brazilian Geophysical Society and do not necessarily represent any position of the SBGf, its officers or members. Electronic reproduction or storage of any part of this paper for commercial purposes without the written consent of the Brazilian Geophysical Society is prohibited.

\begin{abstract}
Performing X-ray computed microtomography (micro-CT) on rock samples allows us to visualize and evaluate the physical properties of the object of study in a non-destructive manner, i.e. without compromising its future use. This study was conducted on carbonatic rocks with stylolites caused by karstic dissolution and, through its application, it is possible to digitally obtain accurate quantitative measurements of the samples' spatial pore system using micro-CT scans. The following method was developed through implementing the standard sequence of Image Processing and Analysis (Gomes, 2001) on ImageJ, a freely available image processing and analysis program. After obtaining the micro-CT scans of a rock sample, they are imported into the software and processed. Segmentation is carried out following the Otsu method and, to determine whether a pixel belongs to the rock matrix or the porous region, a threshold is established and applied to the images. To verify the segmentation's accuracy, total porosity values calculated by the software need to be compared to those obtained during laboratory analysis, in order to adjust the segmentation criteria and, therefore, minimize errors in the porosity estimations. This procedure was performed on 5 (five) samples with a micro-CT voxel resolution of $0,035 \mathrm{~mm}$ and the error margin encountered between the experimental and digital values of total porosity varies between $0,07 \%$ and $3,72 \%$. When applying this technique, it is necessary to take into account the presence of sub-resolution porosity in the samples; the greater the micro-CT images' resolution is, the smaller the error will be when comparing computed values to those obtained by calculating porosity in the laboratory. The described method allows processing micro-CT image sequences using open-source software, which involves little computational costs and limited time consumption. An accurate segmentation allows for future manipulation of the sample's scans on other softwares, where innumerous quantitative analysis and 3D physics simulations can be performed without causing any damage to the original sample. This procedure can generate valuable contributions to the scientific community, as well as to the Oil and Gas industry.
\end{abstract}

Keywords: Petrophysics, X-ray computed microtomography, open-source software. 